\title{
EDUCAÇÃO EM SAÚDE COM ADOLESCENTES NO "PROJETO PESCAR": UMA FORMA DE FAZER EXTENSÃO UNIVERSITÁRIA
}

\author{
Shanna Nascimento ${ }^{1}$ \\ Maycon Fernandes Rocha dos Santos ${ }^{2}$ \\ Helena Portes Sava de Farias ${ }^{3}$ \\ Renata de Oliveira Batista Nakajma ${ }^{4}$ \\ Bruna Ribeiro Alexandre ${ }^{5}$ \\ Cleide Gonçalo Rufino ${ }^{6}$ \\ Julia Tadeu dos Santos e Paula ${ }^{7}$ \\ Fabiana Ferreira Koopmans ${ }^{8}$
}

\begin{abstract}
RESUMO: Na extensão universitária busca-se integrar o saber científico ao saber popular. O presente texto tem o objetivo de descrever as experiências vivenciadas no projeto "Educação em Saúde no Projeto Pescar". A metodologia utilizada foi de abordagem qualitativa, com a descrição do relato da experiência sobre a participação de um grupo de acadêmicos extensionistas do curso de Enfermagem no Projeto Pescar, desenvolvido em parceria com a Universidade e a Usina Gerdau Cosigua. Os resultados apontam que a extensão universitária possibilitou um espaço para ensino-aprendizagem, tanto para os acadêmicos de enfermagem quanto para os adolescentes inseridos no projeto. Conclui que a educação em saúde realizada por meio da extensão, enquanto espaço de formação voltada para o cuidado e como produção de conhecimento, auxilia o indivíduo a realizar escolhas inteligentes, tomada de decisões, mudanças no estilo de vida, para alcançar qualidade e cidadania, independente de condições econômicas sociais existentes.
\end{abstract}

PALAVRAS-CHAVE: Educação em saúde. Extensão universitária. Adolescência.

Health education with adolescents in the "Projeto Pescar": a way of university extension

ABSTRACT: University Extension seeks to integrate scientific knowledge to popular knowledge. This paper aims to describe the experiences in the University Extension Project with adolescents: "Health Education in the Projeto Pescar". The methodology used has been qualitative approach, describing the report of the experience double the participation of a group of academic extension of Nursing in the Projeto Pescar, developed in partnership with the University and Plant Gerdau Cosigua.

\footnotetext{
${ }^{1}$ Graduada em Enfermagem pelo Centro Universitário Augusto Motta (UNISUAM), participante do projeto de extensão "Educação em Saúde" no Projeto Pescar (shanna@hotmail.com).

2 Acadêmico do curso de Enfermagem do Centro Universitário Augusto Motta (UNISUAM), participante do projeto de extensão "Educação em Saúde" no Projeto Pescar (maikonsax10@gmail.com)

${ }^{3}$ Mestranda em Desenvolvimento Local pelo Centro Universitário Augusto Motta (UNISUAM), coordenadora adjunta de estágio na mesma instituição, ex-preceptora do projeto de extensão "Educação em Saúde" no Projeto Pescar (helenasava@gmail.com).

4 Especialista em Nefrologia pela Universidade Gama Filho, preceptora do projeto de extensão "Educação em Saúde" no Projeto Pescar (renfbaptista@hotmail.com).

5 Acadêmica do curso de Enfermagem do Centro Universitário Augusto Motta (UNISUAM), participante do projeto de extensão "Educação em Saúde" no Projeto Pescar (ni-dg@hotmail.com).

${ }^{6}$ Especialista em Enfermagem em Terapia Intensiva pelo Centro Universitário Augusto Motta (UNISUAM), professora e coordenadora de estágio supervisionado do curso de Enfermagem na mesma instituição (cleide_rufino@oi.com.br).

Mestre em Educação pela Universidade Católica de Petrópolis, professora do curso de Pedagogia e coordenadora de projetos de extensão da Zona Oeste do Centro Universitário Augusto Motta (UNISUAM) (jpaula@unisuam.edu.br).

${ }^{8}$ Especialista em Saúde da Família pelo Consórcio do Ministério da Saúde, professora do curso de Enfermagem e coordenadora do curso de Especialização em Saúde da Família do Centro Universitário Augusto Motta (UNISUAM), responsável pelo projeto de extensão "Educação em Saúde" no Projeto Pescar (biasferreira@hotmail.com). 
The results show that the university extension allowed a space for teaching and learning for both nursing students and for adolescents included in the project. It concludes that health education carried through the extension out as training area focused on care and as knowledge production, helps the individual to make intelligent choices, decisions, changes concerning lifestyle, achieving quality and citizenship, regardless of existing social economic condition.

KEYWORDS: Health education. University extension. Adolescence.

\section{INTRODUÇÃO}

Este relato apresenta uma experiência em educação em saúde com adolescentes participantes de um projeto de extensão universitária, desenvolvido pelo Centro Universitário Augusto Motta (UNISUAM) em parceria, desde 2008, com o Projeto Pescar, iniciativa da Usina Metalúrgica Gerdau Cosigua, localizada em Santa Cruz, no município do Rio de Janeiro.

A atuação no projeto ocorreu por meio de atividades de educação em saúde com adolescentes selecionados para participar das ações e foi baseada em oficinas educativas com temas propostos pelos próprios adolescentes. Partiu-se da premissa que, por meio da educação em saúde, compartilhada entre os adolescentes e os acadêmicos, novos saberes surgem, por meio da interação entre os sujeitos, com criação de vínculo, tornando, assim, o encontro muito mais efetivo.

Desta forma, como cita Alves e colaboradores (2008), os adolescentes exercem ações de cidadania nas problemáticas, conhecem os significados dos temas escolhidos, constroem conhecimentos de promoção à saúde e viabilizam a importância de encontros e diálogos entre alunos e professores, a partir do movimento de construção e de troca entre os saberes científicos e populares.

De acordo com Oliveira (2005), existem modelos de educação em saúde. No modelo tradicional, as ações educativas na área estão sempre sob o olhar biomédico, de responsabilidade individual, que "culpa" os indivíduos pela não adesão às orientações, fundamentadas pelo saber científico. Esse enfoque desconsidera o conhecimento prévio do "outro" dos serviços de saúde, utilizando uma abordagem educativa informativa, em que esse "outro" é "preenchido" pelos saberes científicos depositados pelo educador, sem feedback.

Ainda de acordo com Oliveira (2005), Smeke e Oliveira (2001) e Stotz (1993), com o intuito de mudança, uma nova forma de educação em saúde ganhou espaço no contexto de Saúde Pública: o modelo radical de educação em saúde, que se baseia no desenvolvimento da consciência crítica das pessoas e na promoção à saúde, por meio da reflexão sobre a realidade pessoal de cada um, estimulando a busca pela causa coletiva dessa realidade, o que envolve e pressupõe desenvolver um plano de ação para alterar o quadro vivenciado.

Este texto tem como objetivo descrever as atividades realizadas no Projeto Pescar, por meio da reflexão sobre a importância de uma prática educativa pautada na construção de vínculo entre adolescentes e acadêmicos do curso de Enfermagem da UNISUAM. 
O método utilizado foi a descrição, em formato de relato de experiência, sobre uma prática educativa desenvolvida no projeto de extensão com adolescentes. No Projeto Pescar, a metodologia baseia-se na "construção compartilhada do conhecimento", no qual a abordagem com os jovens partiu da criação de um espaço, no qual pudessem ser debatidos assuntos propostos pelos próprios atores, que são os adolescentes.

A metodologia pautada na construção compartilhada do conhecimento é desenvolvida na prática de educação em saúde que considera a experiência cotidiana dos atores envolvidos, e tem por finalidade a conquista, por indivíduos e grupos populares, de maior poder de intervenção nas relações sociais que influenciam a qualidade de vida das pessoas (CARVALHO; ACIOLI; STOTZ, 2001).

Este tipo de prática envolve aspectos tanto de natureza pedagógica quanto metodológica, proposta por Paulo Freire (apud ACIOLI, 2008) numa abordagem construtivista da aprendizagem.

\section{Desenvolvimento do projeto}

Neste Projeto, a criação do espaço interativo com os adolescentes aconteceu dentro do Módulo da Saúde do Projeto Pescar, que, atualmente está presente em Organizações localizadas em 10 estados brasileiros e no Distrito Federal, somando 111 unidades e mais de 13.700 jovens formados.

Além disso, a Fundação Projeto Pescar recebeu vários prêmios em reconhecimento à iniciativa que beneficia Jovem eOrganizações.AFundaçãoétambém certificadora do ProgramaJovemAprendiz, com a visão de ser referência como agente de transformação social de jovens adolescentes (HEMB, 2008).

A missão do Projeto Pescar é implementar, acompanhar e desenvolver, em organizações socialmente responsáveis, oportunidades de qualificação profissional, desenvolvimento pessoal e cidadania para jovens em situação de vulnerabilidade social (HEMB, 2008).

Este projeto faz parte de uma Ação Governamental, sem fins lucrativos, que a Gerdau Cosigua, Usina do Grupo Gerdau, localizada em Santa Cruz, Zona Oeste do Rio de Janeiro desenvolve em parceria com a UNISUAM e com outras instituições privadas e públicas, nacionais e internacionais. O curso desenvolvido pela Gerdau é oferecido para 20 alunos, selecionados das comunidades do entorno da Usina que, neste caso, são adolescentes de Santa Cruz. Uma das exigências para a seleção e a manutenção dos adolescentes no projeto é que eles devem pertencer a famílias de baixa renda e estar estudando em turno diferente daquele em que ocorre o projeto (GOMES; MEDEIROS; SANTOS, 2009).

O Projeto Pescar constitui-se de módulos, com duração de um ano, e acontece nos turnos da manhã, diariamente. Os alunos são selecionados a partir de provas, entrevistas individuais, dinâmicas de grupo e visitas domiciliares.

Desde 2008, acadêmicos extensionistas do Curso de Enfermagem da UNISUAM atuam no Módulo da Saúde do Projeto Pescar, desenvolvendo ações de educação em saúde, no formato de projeto de extensão 
universitária. Selecionados, por meio de provas e entrevistas, esses acadêmicos são capacitados a trabalhar com educação em saúde na metodologia de construção compartilhada do conhecimento.

OMódulodeSaúdedesenvolve-sepormeio de dezencontros, quepodemserplanejadosdeacordocomos coordenadores do Projeto Pescar. Os encontros baseiam-se em oficinas, voltadas para os adolescentes, nas quais são abordados assuntos relacionados à saúde. Entretanto, o objetivo maior está relacionado ao acolhimento destes adolescentes pelo projeto e à interação com os acadêmicos de Enfermagem.

O primeiro dia do Módulo da Saúde é muito importante porque são os próprios adolescentes que escolhem os temas dos encontros. É realizada uma dinâmica interativa entre os adolescentes e acadêmicos de enfermagem, tendo-se percebido que a formação do vínculo está condicionada a forma com que são realizadas essas dinâmicas.

A programação dos outros dias está condicionada aos temas selecionados no primeiro dia do Módulo, podendo haver mudanças decorrentes da interação entre os acadêmicos e adolescentes para escolhas de novos temas, de acordo com a necessidade do grupo e de novas reflexões que possam surgir com o decorrer do tempo.

A maioria dos temas propostos pelos alunos são temas relacionados à sexualidade e doenças sexualmente transmissíveis (DST's) e AIDS, além de questões relacionadas ao corpo e à métodos contraceptivos. Outros temas, como atividades físicas, higiene corporal, higiene bucal, meio ambiente, primeiros socorros com suporte básico de vida, alimentação saudável e reaproveitamento de alimentos, automedicação, anabolizantes e higiene mental, também são muito solicitados.

O formato das oficinas segue a relação da ação-reflexão-ação, em que são realizadas dinâmicas sobre os temas, seguido da discussão do material teórico disponibilizado e, novamente, discussão dos temas a partir do cotidiano desses adolescentes.

Geralmente, cada oficina dura, em média, de três horas, com momentos de acolhimento (a forma como são recebidos os adolescentes), atividade central (tema escolhido previamente, com dinâmica de corte e colagem, pintura, desenhos, aulas práticas, aulas expositivas dialogais, técnicas de relaxamento e meditação, para melhor interação grupal e assimilação de aprendizagem) e avaliação (com aplicação de questionário, redações e exercícios complementares). Desta forma, as oficinas estão baseadas no diálogo/ouvir o outro, tomando como ponto de partida do processo pedagógico o saber anterior das pessoas, resultante de suas experiências e vivências de situações concretas, a troca de experiências e a construção de conhecimento entre o saber técnico e o saber popular.

O Projeto Pescar encontra-se em sua quarta turma de formação e o curso de Enfermagem acompanha o projeto desde o seu início, sendo que a cada ano com maior atuação. Na primeira turma, em 2008, a atuação do curso baseava-se em ministrar aulas do Módulo da Saúde. Na segunda turma, no ano seguinte, atuou também nas atividades com os responsáveis dos adolescentes nas reuniões bimestrais, cujo objetivo foi orientar os pais nas questões de saúde por eles levantadas. Por fim, na terceira turma, o curso atuou inclusive no processo de seleção dos adolescentes, por meio de entrevistas individuais, dinâmicas de grupo e visitas domiciliares. 
Desta forma, compreendemos que a extensão possibilita um espaço para o processo de ensinoaprendizagem, integrando assistência e pesquisa e promovendo questões de cidadania (ALVES, 2005), a proposta neste projeto está sempre demandando a interação e a troca de saberes, numa dinâmica construtiva, criativa, de forma essencialmente transdisciplinar.

\section{CONSIDERAÇÕES FINAIS}

Uma das questões mais relevantes no Projeto Pescar foi perceber a exteriorização de vários aspectos específicos da adolescência que, muitas vezes, são sufocados pelas diversidades da vida, como a vulnerabilidade social, moradia difícil, desemprego e conflito familiar, abandono dos pais, gestação precoce, uso de drogas, e até mesmo participação em grupos de tráfico na comunidade.

Na convivência entre os adolescentes e os acadêmicos, os problemas encontrados no caminho foram minimizados. A criação de vínculo entre os grupos nos mostrou como é possível a transformação do indivíduo por meio da educação em saúde, compartilhada e emancipadora. O abandono de algumas práticas ilícitas, como por exemplo, o uso de anabolizantes por alguns adolescentes, foi observado ao final dos encontros, conforme atestaram muitos deles.

As ações educativas do projeto, muitas vezes exercida de maneira formal, planejada ou de maneira informal, num diálogo durante o café da manhã, almoço ou nos intervalos das aulas, funcionou como um grande elo entre os adolescentes e acadêmicos.

A saúde vista de modo multidimensional, tal como proposta neste projeto, está sempre demandando a interação por meio do acolhimento, do vínculo, da troca de saberes. Se há relação de confiança e diálogo entre as pessoas envolvidas, há a aceitação da proposta de caráter educativo. O convívio e o respeito adquiridos acabam sendo um fator facilitador de ensino junto ao grupo, mais do que o saber técnico.

Para que essas propostas educativas se concretizassem foram necessárias reflexões críticas a partir do diálogo, do ouvir o outro, os saberes práticos do outro, ainda que haja diferenças entre o tempo e a vocação para o ensino e o cotidiano das práticas.

Sendo assim, a Extensão funcionou como um espaço potencial de troca de experiências e saberes, de incorporação de interesses, os quais podem indicar inovações conceituais, suscitando novas formas de pensar, de saber e de fazer ações educativas. Desta forma, a educação em saúde, tornase um instrumento renovador, transformador. 


\section{REFERÊNCIAS}

ACIOLI, S. A prática educativa como expressão do cuidado em saúde pública. Revista Brasileira de Enfermagem, Rio de Janeiro, v. 61, n. 1, p. 117-121, jan.-fev. 2008.

ALVES, V. S. Um modelo de educação em saúde para o Programa da Família: pela integralidade da atenção e reorientação do modelo assistencial. Interface - Comunicação, Saúde, Educação, v. 9, n. 16, p. 39-52, fev. 2005.

CARVALHO, M. A. P.; ACIOLI, S.; STOTZ, E. N. O processo de construção compartilhada do conhecimento: uma experiência de investigação científica do ponto de vista popular. In: VASCONCELOS, E. M. (Org.). A saúde nas palavras e nos gestos: reflexões da rede de educação popular e saúde. São Paulo: Hucitec, 2001.

GOMES, A.; MEDEIROS, L.; SANTOS, J. dos. Projeto Pescar promove desenvolvimento juvenil na Zona Oeste. UNISUAM News, 2009. Disponível em: < http://apl.unisuam.edu.br/portal/ modules.php?name=News\&topo=1\&site=2\&file=article\&sid=224"> . Acesso em: $10 \mathrm{dez} .2010$.

HEMB, R. Fundação Projeto Pescar. Relatórios de Atividades. Porto Alegre, 2008. Disponível em: <http://www.projetopescar.org.br/conteudo/home.asp>. Acesso em: 10 dez. 2010.

OLIVEIRA, D. L. de. A "nova” Saúde Pública e a promoção da saúde via educação: entre a tradição e inovação. Revista Latino-Americana de Enfermagem, Ribeirão Preto, v. 13, n. 3, maio-jun. 2005.

SMEKE, E. L. M.; OLIVEIRA, N. L. S. Educação em saúde e concepções de sujeito. In: VASCONCELOS, E. M. (Org.) A saúde nas palavras e nos gestos: reflexões da rede educação popular e saúde. São Paulo: HUCITEC, 2001.

STOTZ, E. N. Enfoques sobre educação e saúde. In: VALLA, V. V.; STOTZ, E. N. Participação popular, educação e saúde: teoria e prática. Rio de Janeiro: Relume-dumará, 1993.

Submetido em 4 de agosto de 2012.

Aprovado em 15 de janeiro de 2013. 